\title{
Increased fibrillarin expression is associated with tumor progression and an unfavorable prognosis in hepatocellular carcinoma
}

\author{
JING ZHANG ${ }^{1}$, GANG YANG ${ }^{2}$, QIANG $\mathrm{LI}^{2}$ and FEI XIE ${ }^{3}$ \\ Departments of ${ }^{1}$ Gastroenterology and ${ }^{2}$ Hepatobiliary Surgery, Affiliated Hospital of \\ North Sichuan Medical College, Nanchong, Sichuan 637000; ${ }^{3}$ Department of Hepatobiliary Surgery, \\ The First People's Hospital of Neijiang, Neijiang, Sichuan 641000, P.R. China
}

Received June 8, 2020; Accepted November 2, 2020

DOI: $10.3892 / \mathrm{ol} .2020 .12353$

\begin{abstract}
Hepatocellular carcinoma (HCC) is the sixth most common cancer and third most common cause of cancer-associated mortality worldwide. Hepatectomy and liver transplantation are the main treatments for early HCC. Immunotherapy and targeted therapy for advanced HCC have become increasingly popular; however, their clinical benefits are limited. Thus, identification of novel therapeutic targets for advanced HCC remains essential. Fibrillarin (FBL) is an essential nucleolar protein that catalyzes the 2'-O-methylation of ribosomal RNAs. Recently, experimental data have suggested that FBL can influence breast-cancer progression. However, the association between FBL expression and HCC remains known. In the present study, the UALCAN database was used to assess FBL mRNA expression in HCC. Immunohistochemistry analysis was performed to detect FBL protein expression in 139 patients with HCC. In addition, bioinformatic analysis was performed using the UALCAN, the Database for Annotation, Visualization and Integrated Discovery, cBioportal and TargetScan databases. Data were analyzed using Kaplan-Meier curves and the log-rank test, and a Cox proportional hazards regression model. The results demonstrated that FBL expression was significantly higher in tumor tissues compared with para-tumor tissues. Furthermore, high FBL expression was significantly associated with tumor diameter and advanced TNM stage in HCC. High FBL expression also predicted a
\end{abstract}

Correspondence to: Dr Fei Xie, Department of Hepatobiliary Surgery, The First People's Hospital of Neijiang, 31 Tuozhong Lane, Jiaotong Road, Neijiang, Sichuan 641000, P.R. China

E-mail: whitetower@163.com

Abbreviations: FBL, fibrillarin; HCC, hepatocellular carcinoma; IHC, immunohistochemical; TMAs, tissue microarrays; M, median; AFP, $\alpha$-fetoprotein

Key words: hepatocellular carcinoma, fibrillarin, prognosis, methylation, ribosomal shorter overall survival time and disease-free survival time in patients with HCC. Bioinformatics analysis demonstrated that FBL may be regulated by methylation modification. In addition, analyses of functional annotations using the Gene Ontology database indicated that FBL-related genes were predominantly enriched in DNA repair and proliferation-related cell-signaling pathways. Notably, high FBL expression signified larger tumor diameter, advanced tumor stage and a poor prognosis. Taken together, the results of the present study suggest that FBL may be a potential target for HCC treatment.

\section{Introduction}

Hepatocellular carcinoma (HCC) is a common malignant cancer in humans, and the fourth leading cause of cancer-associated morality worldwide $(1,2)$. Globally, from 2004 to 2017, the incidence of hepatocellular carcinoma was 1/100,000 (3), with a low overall 5-year survival rate of $18 \%$ (4). In addition to liver resection and liver transplantation, targeted therapy, immunotherapy and transarterial chemoembolization are used to treat advanced HCC (5-7). However, patients with HCC suffer from a high prevalence of mortality and recurrence (5,7-11). Thus, identification of novel effective targets for the treatment of advanced HCC remains essential.

Ribosomes take part in the synthesis of proteins, as the site of mRNA translation (12). Recently, increasing evidence has demonstrated that ribosomes can regulate cancer progression and drug reactions by 'alternative translation', which enables tumor cells to adapt to their environment in order to proliferate (13-16). Methylation of ribosomal (r)RNA is the primary method to control protein synthesis (17-19).

The nucleolar protein, fibrillarin (FBL) catalyzes the 2'-O-methylation (2'-O-Me) of rRNAs to manage translation of mRNAs $(20,21)$, which enables changes in the combination of rRNAs and specific mRNAs (22-24). FBL can promote cancer-cell proliferation by regulating mRNA translation and controlling the methylation of rRNAs, which has been demonstrated in breast cancer and cancer of the prostate gland $(20,25,26)$.

Marcel et al (20) reported that p53 acts as a safeguard of protein synthesis by regulating FBL expression to inhibit tumor 
occurrence. In addition, reversible acetylation of FBL regulates methylation of nucleolar H2AQ104, thereby reinforcing oscillation of Pol-I transcription during the cell cycle (27). Shubina et al (21) demonstrated the potential roles of FBL in the regulation of cell proliferation, cancer progression and aging. Taken together, these results suggest that FBL may function as an oncogene. However, the function of FBL in HCC and the effect of FBL expression on HCC cells remain unknown.

To investigate the expression difference of FBL in tumor tissues and para-tumor tissues of $\mathrm{HCC}$, immunohistochemistry (IHC) and bioinformatics analyses demonstrated that FBL expression was upregulated in patients with HCC. Furthermore, high FBL expression signified an advanced tumor stage and a poor prognosis. Using publicly available RNA-sequencing data, it was demonstrated that the methylated modification of FBL was frequent in HCC. Taken together, the results of the present study suggest that FBL may regulate the biological behavior of tumor cells by DNA damage/repair, cell-cell adhesion, the cell cycle, as well as signaling pathways involving fibroblast growth factor receptors, epidermal growth factor receptors and nuclear factor- $\kappa \mathrm{B}(\mathrm{NF}-\kappa \mathrm{B})$-inducing kinase/NF- $\mathrm{B}$.

\section{Materials and methods}

Ethical approval of the study protocol. The present study was approved by the Ethics Committee of the Affiliated Hospital of North Sichuan Medical College (Nanchong, China; approval no. 2020ER(A)024; May 29, 2019). Written informed consent was provided by patients, their authorized agents or their close relatives prior to the study start for use of their tissue samples and clinical details.

Study cohort. A total of 139 patients with HCC from the Affiliated Hospital of North Sichuan Medical College formed the study cohort, between June 2014 and December 2016. The present study included 114 men and 25 women with HCC, with an average age of 54.22 years (age range, 36-73 years). HCC was confirmed via histological analysis. A total of $139 \mathrm{HCC}$ tissues and 81 paired para-tumor tissues were selected from patients who had not undergone radiotherapy or chemotherapy prior to surgery. In addition, patients with distant metastasis, Child-Pugh (28) liver function of grade $\mathrm{C}$ or other types of cancer were excluded from the present study. The cancer tissues and corresponding adjacent tissues were applied to produce tissue microarrays (TMAs).

Follow-up. Survival analysis data was obtained via the telephone, the follow-up visit comprised liver-function tests, chest radiography and measurement of $\alpha$-fetoprotein (AFP) expression. Follow-up was at least every 2 months in the first 6 months following surgery, every 3 months for 6 months- 2 years after surgery, and every 6 months for 2-5 years following surgery. If necessary, computed tomography or magnetic resonance imaging were also performed to diagnose tumor recurrence. Postoperative adjuvant therapy and treatment of tumor recurrence were communicated by our multidisciplinary team. Surpassing 5 years post-surgery, the survival of patients with HCC was largely affected by several clinically unrelated factors, for example household income (3), thus the survival of all patients was calculated up to 5 years post-surgery.
IHC analysis. Fresh tissue samples were fixed in $4 \%$ formalin for $24 \mathrm{~h}$ at room temperature, washed five times with PBS (3 min each) and subsequently dehydrated with ethanol. Tissue samples were embedded in paraffin and cut into 4- $\mu$ m-thick sections (diameter of $2 \mathrm{~mm}$ ) to produce TMAs. TMAs were deparaffinized in xylene and rehydrated in a descending ethanol series $(100,95$ and $85 \%)$ at room temperature. TMAs were incubated with $0.3 \% \mathrm{H}_{2} \mathrm{O}_{2}$ to inhibit endogenous peroxidase activity, and antigen-retrieval was subsequently performed with ethylenediamine tetraacetic acid antigen-retrieval solution (Beyotime Institute of Biotechnology; P0085), using a microwave for $15 \mathrm{~min}$. TMAs were blocked with $10 \%$ goat serum (Beijing Solarbio Science \& Technology Co., Ltd.; SL038) for $30 \mathrm{~min}$ at room temperature, and incubated with anti-FBL (1:100; Abcam; cat. no. ab166630) overnight at $4^{\circ} \mathrm{C}$. Following the primary incubation, TMAs were incubated with a secondary antibody for $1 \mathrm{~h}$ at $37^{\circ} \mathrm{C}(1: 1$; Dako; Agilent Technologies, Inc; cat. no. K5007). The REAL ${ }^{\mathrm{TM}}$ EnVision $^{\mathrm{TM}}$ immunohistochemistry kit include the secondary antibody, and the secondary antibody from the manufacturer has come out of the working fluid concentration. The TAMs were color rendered using the REAL ${ }^{\mathrm{TM}}$ EnVision $^{\mathrm{TM}}$ immunohistochemistry kit (Dako; Agilent Technologies, Inc; cat. no. K5007), according to the manufacturer's instructions. To score the expression of FBL in the TMAs, the TMAs were imaged using an automatic immunohistochemical section scanning system (Pannorramic SCAN, Hungary).

IHC scoring. Color intensity was divided into four classifications of staining, as follows: None, score $=0$; weak, score $=1$; moderate, score $=2$ and intense, $s$ core $=3$. The proportion of positive cells was ranked into five levels, as follows: $<5 \%$, score $=0 ; 5-25 \%$, score $=1 ; 26-50 \%$, score $=2 ; 51-74 \%$, score $=3$ and $\geq 75 \%$, score $=4$. Multiplication of the staining score with the score for the percentage of positive cells provided the final score. The cut-off point for high FBL expression was based on the median IHC score -6 (29). Thus, a score $<6$ was classified as low FBL protein expression, while a score $\geq 6$ was classified as high FBL protein expression. Each score was independently evaluated by two experienced pathologists from the Department of Pathology, The First People's Hospital of Neijiang (Neijiang, China). In the case of ambiguity, a third experienced pathologist from the Department of Pathology, The First People's Hospital of Neijiang (Neijiang, China) judged the final outcome.

Bioinformatic analysis. The UALCAN database (ualcan. path.uab.edu) was used to analyze FBL expression in HCC, the methylation level of its promoters and identify the associated genes, which was downloaded from The Cancer Genome Atlas (TCGA) RNA-sequencing data (ualcan.path.uab.edu). The statistical tests were performed via TCGA analysis of UALCAN (Figs. 1A and B, and 3B). FBL expression was assessed in HCC from 50 normal liver tissues and 371 primary tumor tissues. Transcripts per million was used to measure expression. Functional enrichment analysis of the associated genes was performed using the Database for Annotation, Visualization and Integrated Discovery (DAVID 6.7, David. ncifcrf.gov). The Gene Ontology (GO) database (David. 

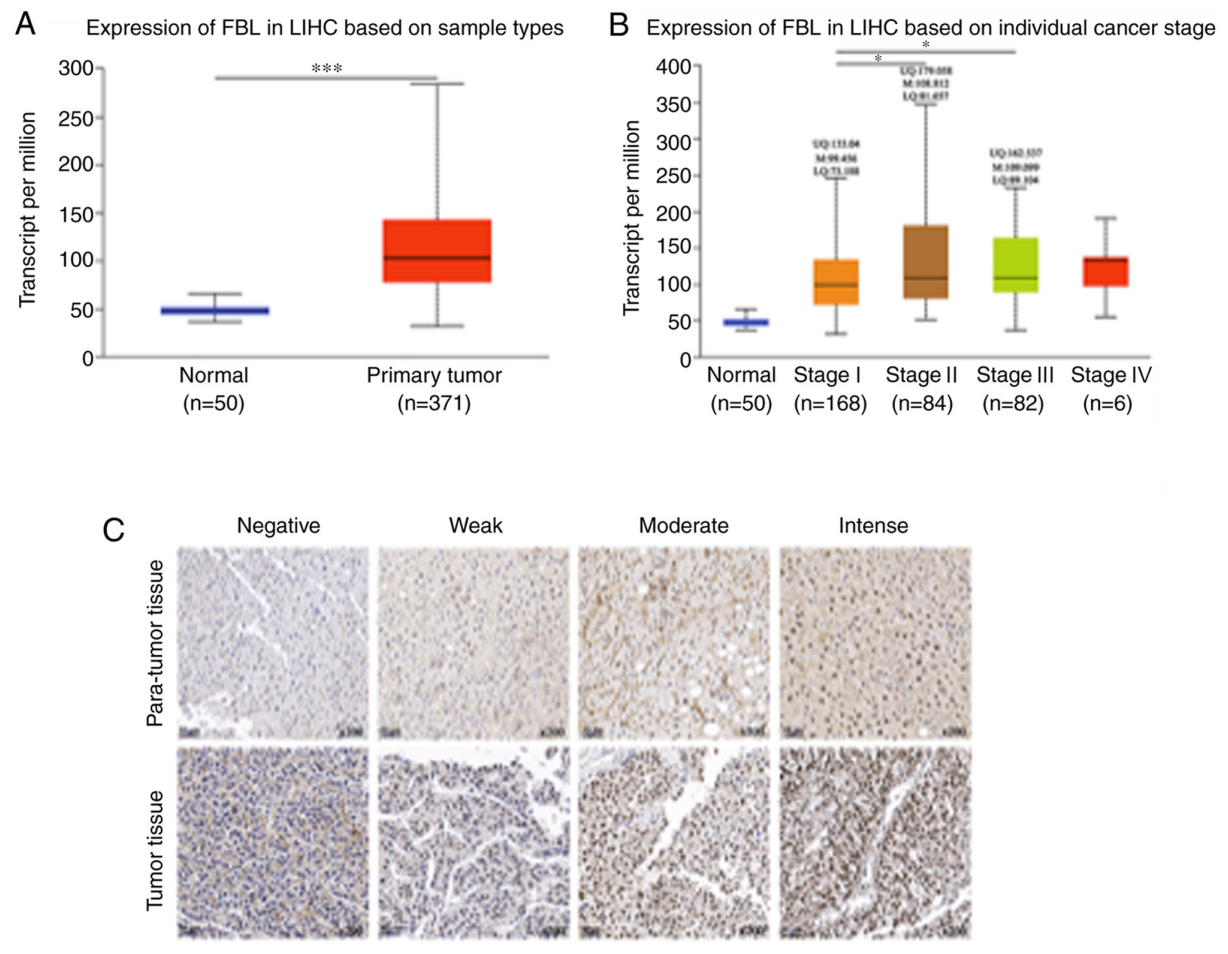

\begin{tabular}{lccc}
\hline Tissue type & High FBL & Low FBL & $\mathrm{P}<0.001$ \\
\hline Tumor tissue & $64(46.0 \%)$ & $75(54.0 \%)$ & 139 \\
Para-tumor tissue & $11(13.6 \%)$ & $70(86.4 \%)$ & 81 \\
\hline
\end{tabular}

Figure 1. Overexpression of mRNA and protein FBL in HCC tissues. (A) Analyses of the UALCAN database demonstrated that FBL mRNA expression was higher in HCC tissues compared with normal liver tissues. (B) The UALCAN database was used to assess FBL mRNA expression in different stages of HCC. (C) Representative images depicting FBL protein expression in adjacent tissues and HCC tissues. (D) The $\chi^{2}$ test was used to assess FBL protein expression in HCC tissues and adjacent tissues. ${ }^{*}<0.05,{ }^{* * *} \mathrm{P}<0.001$. FBL, fibrillarin; HCC, hepatocellular carcinoma; LIHC, liver hepatocellular carcinoma.

ncifcrf.gov) was used to assess 186 FBL-related genes (Person-CC $\geq 0.5$ ). The mutation or amplification of FBL was validated using cBioportal (www.cbioportal.org), which involved four datasets, as follows: INSERM, Nat Genet 2015, 243 samples (30); AMC, Hepatology 2014, 231 samples (31); TCGA, Firehorse Legacy, 442 samples (http://gdac.broadinstitute.org/runs/stddata), Pancancer Atlas, 372 samples (32-41). The micro (mi)RNAs that bind with the 3'-untranslated region (UTR) of FBL were predicted using TargetScan 3.1 (www. targetscan.org). The methylation of promoters was assessed within UALCAN using TCGA RNA-sequencing data. The $\beta$-value indicated the level of DNA methylation ranging from 0 (unmethylated) to 1 (fully methylated).

Statistical analysis. Statistical analysis were performed using SPSS v23 software (IBM Corp.). The $\chi^{2}$ test was for categorical data, as well as to determine the association between FBL protein expression and the clinicopathological characteristics of patients with HCC. Survival analysis was performed using the Kaplan-Meier method and log-rank test. Univariate and multivariate analyses was performed using the Cox proportional hazards model to determine the prognostic values of the risk factors associated with $\mathrm{HCC}$. $\mathrm{P}<0.05$ was considered to indicate a statistically significant difference.

\section{Results}

$F B L$ expression is increased in $H C C$. Analyses of the UALCAN database demonstrated that FBL mRNA expression was higher in HCC tissues compared with normal liver tissues; 50 normal tissues and 371 primary tumor tissues were assessed (Fig. 1A). In addition, high FBL mRNA expression was observed in patients with advanced HCC than those with early HCC (Fig. 1B). A total of 139 tumor tissues and 81 paired para-tumor tissues were used in the present study to assess FBL protein expression. IHC analysis was undertaken by our research team and the results demonstrated that FBL protein was predominantly located in the nuclei, at significantly higher levels in HCC tissues (Fig. 1C; upper panel, para-tumor tissues; lower panel, tumor tissues). Among the 139 tumor tissues, IHC analysis revealed 64 patients $(46.0 \%)$ with high FBL expression. However, among the 81 para-tumor tissues, 11 patients $(13.6 \%)$ had high FBL expression ( $\mathrm{P}<0.001$; Fig. 1D).

Association between FBL expression and clinicopathological characteristics. The study cohort comprised 114 men and 25 women with HCC, and the average age was 54.22 years (Table I). The $\chi^{2}$ test was used to assess the association between FBL expression and the clinicopatho- 
Table I. Association between FBL expression and the clinicopathological characteristics of patients with hepatocellular carcinoma $(\mathrm{n}=139)$.

\begin{tabular}{|c|c|c|c|c|}
\hline Characteristics & No. of patients & High FBL expression $(n=64)$ & Low FBL expression $(n=75)$ & P-value \\
\hline Age, years & $54.22 \pm 10.13$ & $53.17 \pm 11.20$ & $55.12 \pm 9.10$ & 0.260 \\
\hline$<55$ & 73 & $35(47.9 \%)$ & $38(52.1 \%)$ & 0.734 \\
\hline$\geq 55$ & 66 & $29(43.9 \%)$ & $37(56.1 \%)$ & \\
\hline Sex & & & & 0.658 \\
\hline Male & 114 & $51(44.7 \%)$ & $63(55.3 \%)$ & \\
\hline Female & 25 & $13(52.0 \%)$ & $12(48.0 \%)$ & \\
\hline AFP, ng/ml & & & & 0.724 \\
\hline$<400$ & 88 & $42(47.7 \%)$ & $46(52.3 \%)$ & \\
\hline$\geq 400$ & 51 & $22(43.1 \%)$ & $29(56.9 \%)$ & \\
\hline Child-Pugh & & & & 0.845 \\
\hline A & 104 & $47(45.2 \%)$ & $57(54.8 \%)$ & \\
\hline B & 35 & $17(48.6 \%)$ & $18(51.4 \%)$ & \\
\hline HBV infection & & & & 0.327 \\
\hline Negative & 35 & $19(54.3 \%)$ & $16(45.7 \%)$ & \\
\hline Positive & 104 & $45(43.3 \%)$ & $59(56.7 \%)$ & \\
\hline Liver cirrhosis & & & & 0.214 \\
\hline Absent & 50 & $27(54.0 \%)$ & $23(46.0 \%)$ & \\
\hline Present & 89 & $37(41.6 \%)$ & $52(58.4 \%)$ & \\
\hline Tumor size, $\mathrm{cm}$ & $5.39 \pm 3.20$ & $4.18 \pm 2.11$ & $6.81 \pm 3.65$ & $<0.001$ \\
\hline$<5$ & 69 & $19(27.5 \%)$ & $50(72.5 \%)$ & $<0.001$ \\
\hline$\geq 5$ & 70 & $45(64.3 \%)$ & $25(35.7 \%)$ & \\
\hline TNM stage & & & & 0.003 \\
\hline I & 82 & $29(35.4 \%)$ & $53(64.6 \%)$ & \\
\hline II-III & 57 & $35(61.4 \%)$ & $22(38.6 \%)$ & \\
\hline Tumor number & & & & 0.227 \\
\hline 1 & 119 & $52(43.7 \%)$ & $67(56.3 \%)$ & \\
\hline $2-3$ & 20 & $12(60.0 \%)$ & $8(40.0 \%)$ & \\
\hline Tumor differentiation & & & & 0.353 \\
\hline Low/moderate & 99 & $43(43.4 \%)$ & $56(56.6 \%)$ & \\
\hline High & 40 & $21(52.5 \%)$ & $19(47.5 \%)$ & \\
\hline Tumor encapsulation & & & & 0.863 \\
\hline Complete & 56 & $25(44.6 \%)$ & $31(55.4 \%)$ & \\
\hline Incomplete & 83 & $39(47.0 \%)$ & $44(53.0 \%)$ & \\
\hline Recurrence & & & & 0.159 \\
\hline Yes & 107 & $53(49.5 \%)$ & $54(50.5 \%)$ & \\
\hline No & 32 & $11(34.4 \%)$ & $21(65.6 \%)$ & \\
\hline Death & & & & 0.305 \\
\hline Yes & 80 & $40(50.0 \%)$ & $40(50 \%)$ & \\
\hline No & 59 & $24(40.7 \%)$ & $35(59.3 \%)$ & \\
\hline
\end{tabular}

FBL, fibrillarin; AFP, $\alpha$-fetoprotein; HBV, hepatitis B virus; TNM, tumor-node-metastasis.

logical characteristics of patients with HCC. The results demonstrated that high FBL expression was significantly associated with larger tumor diameter $(\mathrm{P}<0.001)$ and advanced TNM stage $(\mathrm{P}=0.003)$. However, no significant associations were observed between FBL expression and age, sex, tumor number, tumor differentiation, infection with the hepatitis-B virus, liver cirrhosis, AFP level and Child-Pugh grade (Table I).

High FBL expression is associated with a poor prognosis in patients with HCC. Kaplan-Meier survival analysis was performed to assess the effect of FBL protein expression on the 
Table II. Univariate and multivariate Cox regression analyses of the risk factors in hepatocellular carcinoma.

\begin{tabular}{|c|c|c|c|c|}
\hline \multirow[b]{2}{*}{ Clinical features } & \multicolumn{2}{|c|}{ Univariate } & \multicolumn{2}{|c|}{ Multivariate } \\
\hline & $\mathrm{HR}(95 \% \mathrm{CI})$ & P-value & $\operatorname{HR}(95 \% \mathrm{CI})$ & P-value \\
\hline \multicolumn{5}{|l|}{ Overall survival } \\
\hline Sex (male vs. female) & $1.026(0.565-1.863)$ & 0.933 & - & - \\
\hline Age, years $(\geq 55$ vs. $<55)$ & $0.999(0.644-1.549)$ & 0.997 & - & - \\
\hline HBV infection (positive vs. negative) & $1.565(0.904-2.709)$ & 0.110 & - & - \\
\hline Liver cirrhosis (present vs. absent) & $1.194(0.747-1.908)$ & 0.458 & - & - \\
\hline Child-Pugh (A vs. B) & $1.217(0.745-1.989)$ & 0.433 & - & - \\
\hline Tumor number (1 ns. 2-3) & $1.520(0.866-2.668)$ & 0.145 & - & - \\
\hline Tumor size, $\mathrm{cm}(\geq 5$ vs. $<5)$ & $2.799(1.761-4.447)$ & $<0.001$ & $2.232(1.377-3.610)$ & 0.001 \\
\hline TNM stage (II-III vs. I) & $2.890(1.849-4.519)$ & $<0.001$ & $2.315(1.456-3.676)$ & $<0.001$ \\
\hline Tumor differentiation (III-IV vs. I-II) & $0.786(0.473-1.305)$ & 0.352 & - & - \\
\hline AFP, ng/ml ( $\geq 400$ vs. $<400)$ & $1.088(0.690-1.717)$ & 0.717 & - & - \\
\hline FBL expression (high vs. low) & $1.610(1.031-2.514)$ & 0.036 & $1.044(0.647-1.684)$ & 0.860 \\
\hline \multicolumn{5}{|l|}{ Disease-free survival } \\
\hline Sex (male vs. female) & $0.987(0.594-1.640)$ & 0.960 & - & - \\
\hline Age, years ( $\geq 55$ vs. $<55)$ & $1.107(0.696-1.487)$ & 0.929 & - & - \\
\hline HBV infection (positive vs. negative) & $1.503(0.940-2.405)$ & 0.089 & - & - \\
\hline Liver cirrhosis (present vs. absent) & $1.238(0.824-1.862)$ & 0.304 & - & - \\
\hline Child-Pugh (A vs. B) & $1.111(0.722-1.710)$ & 0.633 & - & - \\
\hline Tumor number (1 vs. 2-3) & $1.821(1.105-3.002)$ & 0.019 & $1.110(0.630-1.955)$ & 0.718 \\
\hline Tumor size, $\mathrm{cm}(\geq 5$ vs. $<5)$ & $2.377(1.607-3.514)$ & $<0.001$ & $2.058(1.377-3.067)$ & $<0.001$ \\
\hline TNM stage (II-III vs. I) & $2.707(1.830-4.002)$ & $<0.001$ & $2.375(1.690-3.546)$ & $<0.001$ \\
\hline Tumor differentiation (III-IV vs. I-II) & $1.208(0.818-1.786)$ & 0.342 & - & - \\
\hline AFP, ng/ml ( $\geq 400$ vs. $<400)$ & $1.165(0.787-1.724)$ & 0.447 & - & - \\
\hline FBL expression (high vs. low) & $1.721(1.169-2.533)$ & 0.006 & $1.267(0.834-1.927)$ & 0.267 \\
\hline
\end{tabular}

HR, hazard ratio; CI, confidence interval; HBV, hepatitis B virus; TNM, tumor-node-metastasis; AFP, $\alpha$-fetoprotein; FBL, fibrillarin. '-', not available.
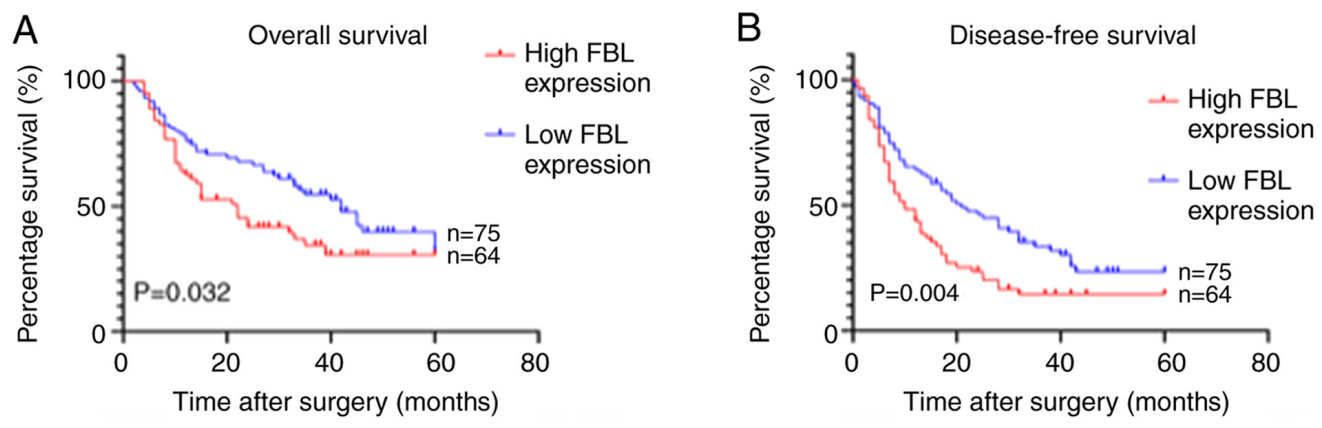

Figure 2. High FBL expression is associated with a poor prognosis in patients with hepatocellular carcinoma. Kaplan-Meier survival analysis demonstrated that patients with high FBL expression had a shorter (A) overall survival time and (B) disease-free survival time. FBL, fibrillarin.

survival of patients with HCC. The results demonstrated that overall survival time $(\mathrm{P}=0.032)$ and disease-free survival time $(\mathrm{P}=0.004)$ were significantly shorter in the high $\mathrm{FBL}$ expression group compared with the low FBL expression group (Fig. 2). Cox regression analysis was subsequently performed to determine the prognostic values of the risk factors in patients with HCC. As presented in Table II, univariate analysis demonstrated that high FBL expression $(\mathrm{P}=0.036)$, tumor diameter $(\mathrm{P}<0.001)$ and
TNM stage $(\mathrm{P}<0.001)$ predicted a shorter overall survival time, while high FBL expression $(\mathrm{P}=0.006)$, tumor diameter $(\mathrm{P} 0.001)$, TNM stage $(\mathrm{P}<0.001)$ and tumor number $(\mathrm{P}=0.019)$ predicted a shorter disease-free survival time. Notably, multivariate analysis demonstrated that high FBL expression was not an independent risk factor for overall survival and disease-free survival time, suggesting that FBL mainly affects the prognosis of patients with HCC by promoting tumor progression (Table II). 

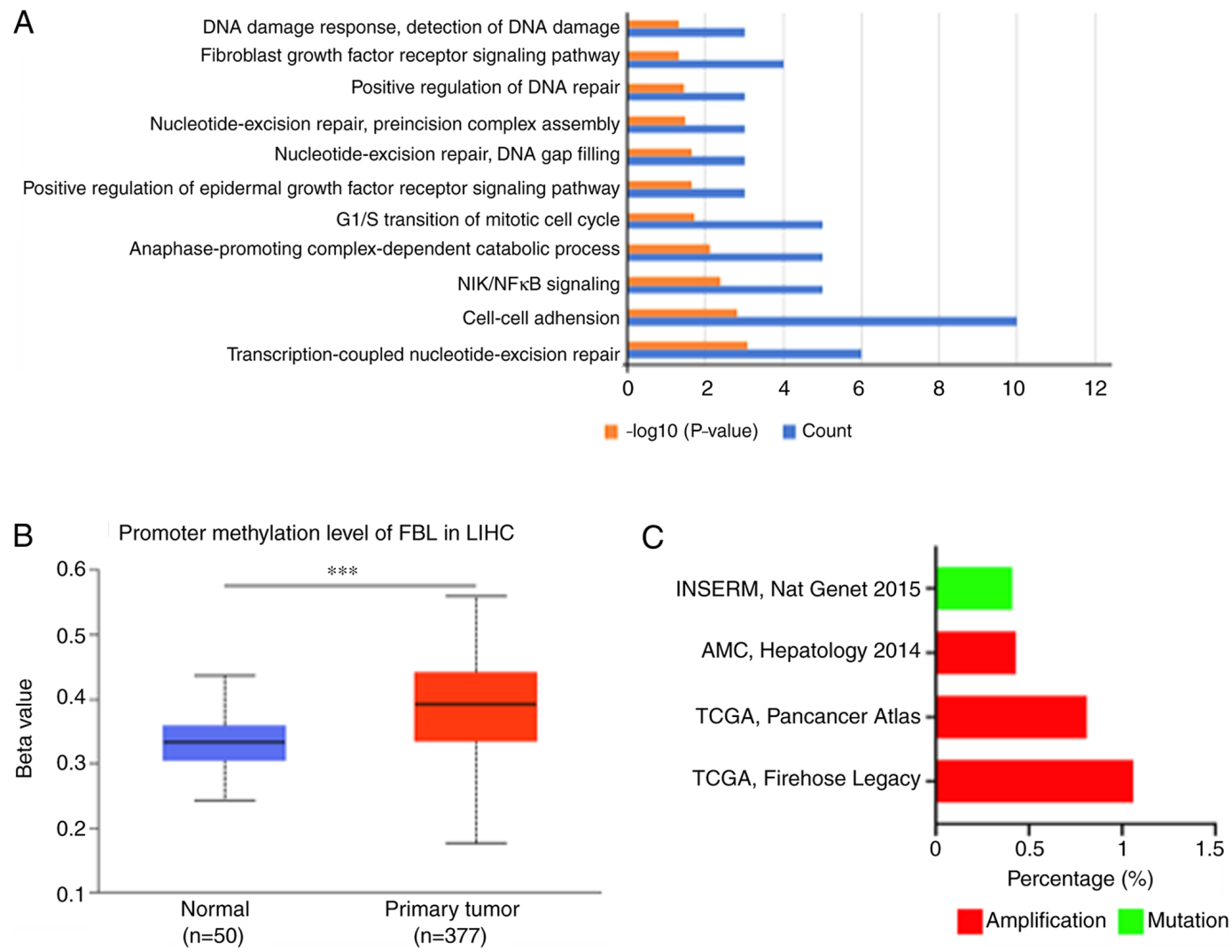

Figure 3. Bioinformatics analysis of the potential regulatory mechanism of FBL expression and FBL-related enrichment of gene function. (A) Analysis of 186 significantly associated genes (Person-CC $\geq 0.5$ ) using the Gene Ontology database (only cancer-associated biological processes are presented). (B) Methylation of the promoters of FBL in HCC using the UALCAN database. (C) Analyses of the mutation and amplification of the FBL gene in HCC using the cBioportal database. ${ }^{* * *} \mathrm{P}<0.001$. FBL, fibrillarin; HCC, hepatocellular carcinoma; LIHC, liver hepatocellular carcinoma.

Bioinformatics analysis of FBL-related genes and the potential regulatory mechanism of FBL expression. The UALCAN database was used to identify genes associated with FBL. The results demonstrated that 186 genes (Person-CC $\geq 0.5$ ) were significantly associated with the FBL gene. Functional enrichment analysis using the DAVID and GO databases demonstrated a majority of biological processes and signaling pathways associated with cancer progression, such as 'cell-cell adhesion', 'G1/S transition of mitotic cell cycle' and 'positive regulation of epidermal growth factor receptor signaling pathway'. The notable cancer-associated biological processes are presented in Fig. 3A. The molecular mechanisms regulating FBL expression are poorly understood $(21,42)$. Using publicly available data, it was demonstrated that methylation of the FBL promoter was high (Fig. 3B); however, the frequency of amplification and mutation was notably low in HCC (Fig. 3C). The miRNAs that may bind with the 3'-UTR of the FBL gene were predicted using TargetScan; however, no conserved miRNAs were identified for FBL. Taken together, these results suggest that FBL expression is mainly regulated by methylation.

\section{Discussion}

The prognosis of patients with $\mathrm{HCC}$ is poor (43-45), thus understanding the pathogenesis, development, invasion, and metastasis of HCC cells remains vital. The results of the present study demonstrated high FBL expression in HCC tissues compared with Para-tumor tissues. In addition, FBL expression was signifi- cantly associated with the diameter and TNM stage of tumors, and high FBL expression signified shorter overall survival time and disease-free survival time in patients with HCC.

The ribosome is a complex "molecular machine" composed of distinct proteins and nucleic acids, and is responsible for protein synthesis $(46,47)$. A broader role for dysregulated ribosome biogenesis has been reported during the development and progression of most types of malignant cancer (47-49). Ribosomes can regulate some oncogenes and tumor suppressors by alternatively translating specific mRNAs, such as p27, p53 and vascular endothelial growth factor (50-52).

Modifications of rRNA have important roles in regulating ribosome function (53), and 2'-O-Me is the most common modification $(23,24,54)$. rRNA methylation can change the combination of specific mRNAs and ribosomes to regulate protein expression $(18,24)$. FBL plays a key role in 2'-O-Me, whereby changes in FBL expression notably affect the translation process (23). Thus, FBL can affect the course of some cellular processes (55-57). Marcel et al (20) reported that high FBL expression is an independent marker of a poor outcome in breast cancer, and that FBL can induce proliferation of MCF7 cells by regulating rRNA methylation. In addition, FBL is required for proliferation, clonogenic survival and appropriate rRNA accumulation/processing in human prostate cancer cells (25). However, the results of the present study demonstrated that high FBL expression was a predictive factor for poor prognosis, advanced tumor stage and large tumor diameter in HCC. 
Koh et al demonstrated that the classical oncogene, MYC can induce FBL overexpression to accelerate prostate cancer (25). As a tumor-suppressor gene, p53 can safeguard protein synthesis by suppressing FBL expression and regulating the subsequent quality and intrinsic activity of ribosomes (20). El Hassouni et al reported that FBL inhibition prior to interaction with $\mathrm{C} / \mathrm{D}$ box snoRNA is an ideal target to inhibit ribosome biogenesis during cancer therapy (58). To further determine the regulatory mechanism of FBL, the UALCAN, cBioportal and TargetScan databases were used. The UALCAN database predicted highly frequent methylation of FBL in HCC. Using publicly available sequencing data, low frequencies of amplifications and mutations were demonstrated in HCC. Furthermore, no conserved miRNAs were identified for FBL according to the TargetScan database. Taken together, these results suggest that methylation may be the main cause for FBL overexpression in HCC. In the present study, KEGG analysis demonstrated that the function of FBL correlated genes was mainly associated with the occurrence and development of tumors.

To the best of our knowledge, the present study was the first to assess the association between FBL expression and the clinicopathological characteristics of patients with HCC, as well as determine the prognostic and predictive values of FBL in HCC. The results demonstrated that FBL was highly expressed in HCC and may accelerate HCC; however, the regulatory mechanism of FBL remains unknown. Taken together, the results of the present study suggest that FBL may be an ideal target for HCC therapy.

\section{Acknowledgements}

The authors of the present study would like to thank Dr Qiang Li and Gang Yang (Department of Hepatobiliary Surgery, Affiliated Hospital of North Sichuan Medical College), for supplying the tissue samples and clinical information of patients.

\section{Funding}

Not applicable.

\section{Availability of data and materials.}

Data sharing is not applicable to this article, as no datasets were generated or analyzed during the present study.

\section{Authors' contribution}

FX conceived the present study. JZ drafted the initial manuscript, and performed immunohistochemistry and statistical analyses. GY and QL collected the tissue samples and analyzed patient's clinical information. All authors contributed to the critical revision of the article for important intellectual content. All authors have read and approved the final manuscript.

\section{Ethics approval and consent to participate}

The present study was approved by the Ethics Committee of the Affiliated Hospital of North Sichuan Medical College (Nanchong, China; approval no. 2020ER(A)024; May 29,
2019). Written informed consent was provided by patients or their close relatives prior to the study start for use of their tissue samples and clinical details.

\section{Patient consent for publication}

Not applicable.

\section{Competing interests}

The authors declare that they have no competing interests.

\section{References}

1. McGlynn KA, Petrick JL and London WT: Global epidemiology of hepatocellular carcinoma: An emphasis on demographic and regional variability. Clin Liver Dis 19: 223-238, 2015.

2. Villanueva A: Hepatocellular Carcinoma. Reply. N Engl J Med 381: e2, 2019. Reply.

3. Wong RJ, Kim D, Ahmed A and Singal AK: Patients with hepatocellular carcinoma from more rural and lower income households have more advanced tumor stage at diagnosis and significantly higher mortality. Cancer cncr.33211, 2020.

4. Javadian P and Nezhat F: Endometrial carcinoma and its precursors. Adv Exp Med Biol 1242: 59-72, 2020.

5. Couri T and Pillai A: Goals and targets for personalized therapy for HCC. Hepatol Int 13: 125-137, 2019.

6. Raoul JL, Forner A, Bolondi L, Cheung TT, Kloeckner R and de Baere T: Updated use of TACE for hepatocellular carcinoma treatment: How and when to use it based on clinical evidence. Cancer Treat Rev 72: 28-36, 2019.

7. Raza A and Sood GK: Hepatocellular carcinoma review: Current treatment, and evidence-based medicine. World $\mathbf{J}$ Gastroenterol 20: 4115-4127, 2014.

8. Fu J and Wang H: Precision diagnosis and treatment of liver cancer in China. Cancer Lett 412: 283-288, 2018.

9. Llovet JM, Montal R, Sia D and Finn RS: Molecular therapies and precision medicine for hepatocellular carcinoma. Nat Rev Clin Oncol 15: 599-616, 2018.

10. Rashed WM, Kandeil MAM, Mahmoud MO and Ezzat S: Hepatocellular carcinoma (HCC) in Egypt: A comprehensive overview. J Egypt Natl Canc Inst 32: 5, 2020.

11. Waidmann O: Recent developments with immunotherapy for hepatocellular carcinoma. Expert Opin Biol Ther 18: 905-910, 2018.

12. Mauro VP and Matsuda D: Translation regulation by ribosomes: Increased complexity and expanded scope. RNA Biol 13: 748-755, 2016.

13. Gentilella A, Kozma SC and Thomas G: A liaison between mTOR signaling, ribosome biogenesis and cancer. Biochim Biophys Acta 1849: 812-820, 2015.

14. Lawrence MG, Obinata D, Sandhu S, Selth LA, Wong SQ, Porter LH, Lister N, Pook D, Pezaro CJ, Goode DL, et al: Patient-derived models of abiraterone- and enzalutamide-resistant prostate cancer reveal sensitivity to ribosome-directed therapy. Eur Urol 74: 562-572, 2018.

15. Mugridge JS and Gross JD: Decapping enzymes STOP 'cancer' ribosomes in their tracks. EMBO J 37: e100801, 2018.

16. Sriram A, Bohlen J and Teleman AA: Translation acrobatics: how cancer cells exploit alternate modes of translational initiation. EMBO Rep 19: e45947, 2018.

17. Dunn S, Lombardi O and Cowling VH: c-Myc co-ordinates mRNA cap methylation and ribosomal RNA production. Biochem J 474: 377-384, 2017.

18. Monaco PL, Marcel V, Diaz JJ and Catez F: 2'-O-methylation of ribosomal RNA: towards an epitranscriptomic control of translation? Biomolecules 8: 106, 2018.

19. Sergiev PV, Aleksashin NA, Chugunova AA, Polikanov YS and Dontsova OA: Structural and evolutionary insights into ribosomal RNA methylation. Nat Chem Biol 14: 226-235, 2018.

20. Marcel V, Ghayad SE, Belin S, Therizols G, Morel AP, Solano-Gonzàlez E, Vendrell JA, Hacot S, Mertani HC, Albaret MA, et al: p53 acts as a safeguard of translational control by regulating fibrillarin and rRNA methylation in cancer. Cancer Cell 24: 318-330, 2013. 
21. Shubina MY, Musinova YR and Sheval EV: Proliferation, cancer, and aging-novel functions of the nucleolar methyltransferase fibrillarin? Cell Biol Int 42: 1463-1466, 2018.

22. Ayadi L, Galvanin A, Pichot F, Marchand V and Motorin Y: RNA ribose methylation (2'-O-methylation): Occurrence, biosynthesis and biological functions. Biochim Biophys Acta Gene Regul Mech 1862: 253-269, 2019.

23. Erales J, Marchand V, Panthu B, Gillot S, Belin S, Ghayad SE, Garcia M, Laforêts F, Marcel V, Baudin-Baillieu A, et al: Evidence for rRNA 2'-O-methylation plasticity: Control of intrinsic translational capabilities of human ribosomes. Proc Natl Acad Sci USA 114: 12934-12939, 2017.

24. Li L, Miao W, Williams P, Guo C and Wang Y: SLIRP interacts with helicases to facilitate 2'-O-methylation of rRNA and to promote translation. J Am Chem Soc 141: 10958-10961, 2019.

25. Koh CM, Gurel B, Sutcliffe S, Aryee MJ, Schultz D, Iwata T, Uemura M, Zeller KI, Anele U, Zheng Q, et al: Alterations in nucleolar structure and gene expression programs in prostatic neoplasia are driven by the MYC oncogene. Am J Pathol 178: 1824-1834, 2011.

26. Su H, Xu T, Ganapathy S, Shadfan M, Long M, Huang TH, Thompson I and Yuan ZM: Elevated snoRNA biogenesis is essential in breast cancer. Oncogene 33: 1348-1358, 2014.

27. Iyer-Bierhoff A and Grummt I: Stop-and-Go: Dynamics of nucleolar transcription during the cell cycle. Epigenet Insights 12: 2516865719849090,2019

28. Tsoris A and Marlar CA: Use Of The Child Pugh Score In Liver Disease. StatPearls Publishing, Treasure Island, FL, 2020

29. Jing JS, Li H, Wang SC, Ma JM, Yu LQ and Zhou H: NDRG3 overexpression is associated with a poor prognosis in patients with hepatocellular carcinoma. Biosci Rep 38: BSR20180907, 2018.

30. Schulze K, Imbeaud S, Letouzé E, Alexandrov LB, Calderaro J, Rebouissou S, Couchy G, Meiller C, Shinde J, Soysouvanh F, et al: Exome sequencing of hepatocellular carcinomas identifies new mutational signatures and potential therapeutic targets. Nat Genet 47: 505-511, 2015.

31. Ahn SM, Jang SJ, Shim JH, Kim D, Hong SM, Sung CO, Baek D, Haq F, Ansari AA, Lee SY, et al: Genomic portrait of resectable hepatocellular carcinomas: Implications of RB1 and FGF19 aberrations for patient stratification. Hepatology 60: 1972-1982, 2014.

32. Bhandari V, Hoey C, Liu LY, Lalonde E, Ray J, Livingstone J, Lesurf R, Shiah YJ, Vujcic T, Huang X, et al: Molecular landmarks of tumor hypoxia across cancer types. Nat Genet 51 308-318, 2019

33. Bonneville R, Krook MA, Kautto EA, Miya J, Wing MR, Chen HZ, Reeser JW, Yu L and Roychowdhury S: Landscape of microsatellite instability across 39 cancer types. JCO Precis Oncol 2017: PO.17.00073, 2017.

34. Ding L, Bailey MH, Porta-Pardo E, Thorsson V, Colaprico A, Bertrand D, Gibbs DL, Weerasinghe A, Huang KL, Tokheim C, et al; Cancer Genome Atlas Research Network: Perspective on oncogenic processes at the end of the beginning of cancer genomics. Cell 173: 305-320.e10, 2018

35. Ellrott K, Bailey MH, Saksena G, Covington KR, Kandoth C, Stewart C, Hess J, Ma S, Chiotti KE, McLellan M, et al; MC3 Working Group; Cancer Genome Atlas Research Network: Scalable open science approach for mutation calling of tumor exomes using multiple genomic pipelines. Cell Syst 6: 271-281.e7, 2018.

36. Gao Q, Liang WW, Foltz SM, Mutharasu G, Jayasinghe RG, Cao S, Liao WW, Reynolds SM, Wyczalkowski MA, Yao L, et al; Fusion Analysis Working Group; Cancer Genome Atlas Research Network: Driver fusions and their implications in the development and treatment of human cancers. Cell Rep 23 . 227-238.e3, 2018.

37. Hoadley KA, Yau C, Hinoue T, Wolf DM, Lazar AJ, Drill E, Shen R, Taylor AM, Cherniack AD, Thorsson V, et al; Cancer Genome Atlas Network: Cell-of-origin patterns dominate the molecular classification of 10,000 tumors from 33 types of cancer. Cell 173: 291-304.e6, 2018.

38. Liu J, Lichtenberg T, Hoadley KA, Poisson LM, Lazar AJ, Cherniack AD, Kovatich AJ, Benz CC, Levine DA, Lee AV, et al; Cancer Genome Atlas Research Network: An integrated TCGA pan-cancer clinical data resource to drive high-quality survival outcome analytics. Cell 173: 400-416.e11, 2018.

39. Poore GD, Kopylova E, Zhu Q, Carpenter C, Fraraccio S, Wandro S, Kosciolek T, Janssen S, Metcalf J, Song SJ, et al: Microbiome analyses of blood and tissues suggest cancer diagnostic approach. Nature 579: 567-574, 2020.
40. Sanchez-Vega F, Mina M, Armenia J, Chatila WK, Luna A, La KC, Dimitriadoy S, Liu DL, Kantheti HS, Saghafinia S, et al; Cancer Genome Atlas Research Network: Oncogenic signaling pathways in The Cancer Genome Atlas. Cell 173: 321-337.e10, 2018.

41. Taylor AM, Shih J, Ha G, Gao GF, Zhang X, Berger AC, Schumacher SE, Wang C, Hu H, Liu J, et al; Cancer Genome Atlas Research Network: Genomic and functional approaches to understanding cancer aneuploidy. Cancer Cell 33: 676-689.e3, 2018.

42. Rodriguez-Corona U, Sobol M, Rodriguez-Zapata LC, Hozak P and Castano E: Fibrillarin from Archaea to human. Biol Cell 107: $159-174,2015$.

43. Ascione A, Fontanella L, Imparato M, Rinaldi L and De Luca M: Mortality from cirrhosis and hepatocellular carcinoma in Western Europe over the last 40 years. Liver Int 37: 1193-1201, 2017.

44. Beal EW, Tumin D, Kabir A, Moris D, Zhang XF, Chakedis J, Washburn K, Black S, Schmidt CM and Pawlik TM: Trends in the mortality of hepatocellular carcinoma in the United States. J Gastrointest Surg 21: 2033-2038, 2017.

45. Weaver AJ, Stafford R, Hale J, Denning D and Sanabria JR; GBD Collaborators: Geographical and temporal variation in the incidence and mortality of hepato-pancreato-biliary primary malignancies: 1990-2017. J Surg Res 245: 89-98, 2020.

46. Brandman O and Hegde RS: Ribosome-associated protein quality control. Nat Struct Mol Biol 23: 7-15, 2016.

47. van Riggelen J, Yetil A and Felsher DW: MYC as a regulator of ribosome biogenesis and protein synthesis. Nat Rev Cancer 10: 301-309, 2010.

48. Arthurs C, Murtaza BN, Thomson C, Dickens K, Henrique R, Patel HRH, Beltran M, Millar M, Thrasivoulou C and Ahmed A: Expression of ribosomal proteins in normal and cancerous human prostate tissue. PLoS One 12: e0186047, 2017.

49. Sulima SO, Kampen KR, Vereecke S, Pepe D, Fancello L, Verbeeck J, Dinman JD and De Keersmaecker K: Ribosomal lesions promote oncogenic mutagenesis. Cancer Res 79: 320-327, 2019.

50. Bellodi C, Kopmar N and Ruggero D: Deregulation of oncogene-induced senescence and p53 translational control in X-linked dyskeratosis congenita. EMBO J 29: 1865-1876, 2010.

51. Bellodi C, Krasnykh O, Haynes N, Theodoropoulou M, Peng G, Montanaro L and Ruggero D: Loss of function of the tumor suppressor DKC1 perturbs p27 translation control and contributes to pituitary tumorigenesis. Cancer Res 70: 6026-6035, 2010.

52. Rocchi L, Pacilli A, Sethi R, Penzo M, Schneider RJ, Treré D, Brigotti $\mathrm{M}$ and Montanaro L: Dyskerin depletion increases VEGF mRNA internal ribosome entry site-mediated translation. Nucleic Acids Res 41: 8308-8318, 2013.

53. Sloan KE, Warda AS, Sharma S, Entian KD, Lafontaine DLJ and Bohnsack MT: Tuning the ribosome: The influence of rRNA modification on eukaryotic ribosome biogenesis and function. RNA Biol 14: 1138-1152, 2017

54. Nachmani D, Bothmer AH, Grisendi S, Mele A, Bothmer D, Lee JD, Monteleone E, Cheng K, Zhang Y, Bester AC, et al: Germline NPM1 mutations lead to altered rRNA 2'-O-methylation and cause dyskeratosis congenita. Nat Genet 51: 1518-1529, 2019.

55. Amin MA, Matsunaga S, Ma N, Takata H, Yokoyama M, Uchiyama S and Fukui K: Fibrillarin, a nucleolar protein, is required for normal nuclear morphology and cellular growth in HeLa cells. Biochem Biophys Res Commun 360: 320-326, 2007.

56. Bouffard S, Dambroise E, Brombin A, Lempereur S, Hatin I, Simion M, Corre R, Bourrat F, Joly JS and Jamen F: Fibrillarin is essential for S-phase progression and neuronal differentiation in zebrafish dorsal midbrain and retina. Dev Biol 437: 1-16, 2018.

57. Newton K, Petfalski E, Tollervey D and Cáceres JF: Fibrillarin is essential for early development and required for accumulation of an intron-encoded small nucleolar RNA in the mouse. Mol Cell Biol 23: 8519-8527, 2003

58. El Hassouni B, Sarkisjan D, Vos JC, Giovannetti E and Peters GJ: Targeting the Ribosome Biogenesis Key Molecule Fibrillarin to Avoid Chemoresistance. Curr Med Chem 26: 6020-6032, 2019.

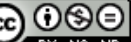

This work is licensed under a Creative Commons Attribution-NonCommercial-NoDerivatives 4.0 International (CC BY-NC-ND 4.0) License. 